\title{
Development and Performance Evaluation of a Two-row Mechanical Paddy Transplanter
}

\author{
Sapunii Sebastian, E.V. Thomas
}

10.18805/ag.D-5328

\begin{abstract}
Background: Paddy is one of the most important staple food in most south-east Asian countries. It is grown either by direct sowing or by transplanting under wetland conditions depending upon the availability of water. India produces 116.48 million tonnes of rice with a productivity of $2659 \mathrm{~kg} \mathrm{ha}^{-1}$. Manual transplanting of rice seedlings by hand is generally done in stooping posture which is laborious and drudgery. It also requires a huge amount of labour during peak season. Considering the need and to suit the hilly region, a tworow manually operated paddy transplanter was developed.

Methods: For picking the seedlings, a four-bar mechanism was selected as the basis of design. The machine construction consists of a float, seedling tray, fixed-fork type finger, chain sprocket system and lugged wheel. For operation, the operator has to rotate the crank handle which transmits the motion through the chain sprocket system and four-bar linkage which in turn picks the seedlings and plants them onto the soil.

Result: The machine was tested in the actual field condition and was working satisfactorily. The designed fixed fork-type finger can hold 5 to 8 seedlings at a time. The developed machine was found to be comfortable working at a speed of $0.5 \mathrm{kmph}$. The actual field capacity of the machine was $0.02 \mathrm{ha} / \mathrm{h}$.
\end{abstract}

Key words: Coupler curve, Fixed fork finger, Four-bar mechanism, Paddy transplanter, Root washed seedlings.

\section{INTRODUCTION}

India is the second-largest producer and consumer of rice in the world after China. On average, India produces $2.2 \mathrm{t} /$ ha (Anon, 2013). Rice can be grown by transplanting seedlings in flooded field conditions or by direct sowing of sprouted seedlings depending upon the availability of water (Gaikwad et al., 2014). Japan developed the first rice transplanter during industrialization and it was patented in the year 1898 (Chaitanya et al., 2018). The use of mechanical device for paddy transplanting started in 1955 in Taiwan when a gravity-type hand-operated transplanter was developed.

In India, A 4-row machine is first tested at TTC Budhni and CRRI Cuttack in 1966 but was found to have limitations like higher labor requirements. (Anonymous, 1979; Dixit et al., 2007).

Most paddy transplanters used planar four-bar linkage mechanisms with the planting finger forming a coupler point (Singh et al., 1981; Thomas, 2002). Transplanting by machine saved $45 \%$ cost of operation and $50 \%$ labour as compared to manual transplanting (Dixit et al., 2007).

Power-operated machine, although has high field capacity, is not feasible due to terrain conditions and smaller land holdings in hilly areas. The cost of operation and repair and maintenance facilities also restrict the use of the machine in remote hilly village areas. Considering all these shortcomings, a suitable lightweight and cost-effective machine are needed to mechanize in areas where manual transplantation is still followed. This will result in reducing the labour work and time consumption.
Indian Institute of Technology, Kharagpur-721 302, West Bengal, India.

Corresponding Author: Sapunii Sebastian, School of Agro and Rural Technology, Indian Institute of Technology, Guwahati-781 039, Assam, India. Email: sapusebastian@gmail.com

How to cite this article: Sebastian, S. and Thomas, E.V. (2021). Development and Performance Evaluation of a Two-row Mechanical Paddy Transplanter. Agricultural Science Digest. DOI: 10.18805/ ag.D-5328.

Submitted: 23-03-2021 Accepted: 30-07-2021 Online: 23-08-2021

\section{MATERIALS AND METHODS}

The work was carried out in the Agricultural and Food Engineering Department, IIT Kharagpur, West Bengal during the year 2017-2018.

Various instruments used for experimentations and measurements include Vernier calipers-for measuring girth area of seedlings and various dimensions of different components of the machine, stopwatch-for measuring the speed of operation, scales-for measuring height of seedlings etc, load cell with indicator-for measuring the force required to pull the machine and measuring tape.

The following methods were used for determining different parameters.

\section{Procedure for deciding link length}

(a) A four-bar mechanism was selected for movement of various linkages. For deciding link length, Grashoff's law was primarily introduced which states that the sum of shortest 


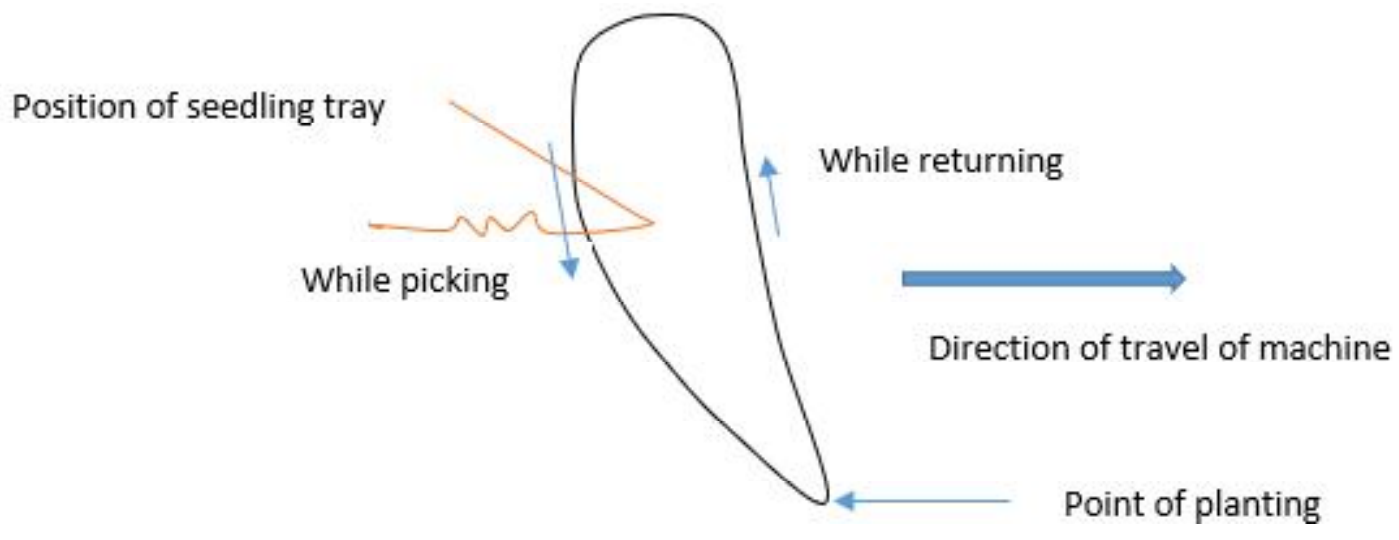

Fig 1: Tracing suitable path for finger movement.

link and longest link should be less than equal to the sum of remaining links. By keeping one link fixed, the other link lengths were decided on a trial and error basis which should follow the different path while picking the seedlings from the tray and while returning. The finger which is the extension of the coupler should follow a path as shown in Fig 1.

\section{b) Determination of base area of seedlings}

The picking finger can be designed based on the area of girth of the seedling where the finger should hold before planting into the puddled soil.

Fig 2 shows location of the seedling to be held at section $A A^{\prime}$ by the transplanter finger. The cross section at $A A^{\prime}$ is approximated to an ellipse with major axis 'a' and minor axis 'b' (Choudhury A.K., 1983). The representation of major and minor axes is shown in Fig 3.

The area of cross section can be calculated by using the relationship

Where,

$$
A=\pi \times a \times b
$$

$A=$ Cross sectional area of the seedling

$a=$ Major axis, $b=$ minor axis

\section{c) Size of finger opening}

The size of finger opening is determined by using the relationship

Size of finger opening $=$

(No. of seedlings per hillx Average area of girth cross section at section $\mathrm{AA}^{\prime}$ )

\section{Packing factor}

The average number of seedlings per hill can be considered to be 5 (Wang et al., 2010).

Average area of cross section of seedlings $=12.24 \mathrm{~mm}^{2}$ (Table 2)

Packing factor $=0.7$ (Assumed)

Therefore

required size of finger opening $=\frac{5 \times 12.24}{0.7}=87.43 \mathrm{~mm}^{2}$

The area of opening of the finger is approximately square in shape. Therefore, Dimension of square $=9.35$ $\mathrm{mm} 10 \mathrm{~mm} \simeq$. Say, a $10 \mathrm{~mm} \times 10 \mathrm{~mm}$ area was chosen.

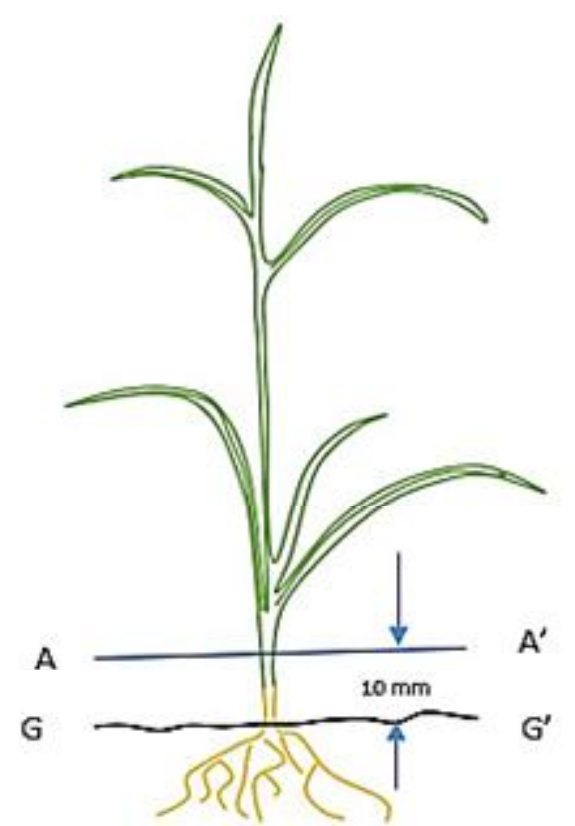

Fig 2: Sketch of a seedling used for transplanting.

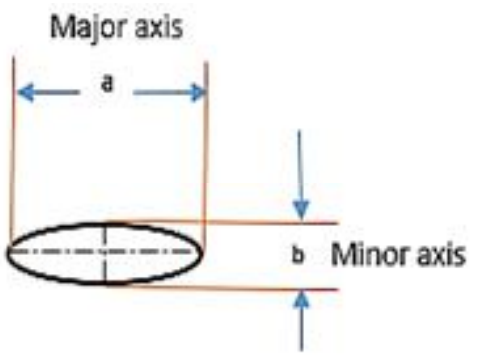

Fig 3: Shape of Cut sectional view of paddy seedling base showing minor and major axis.

\section{d) Hill to hill spacing}

This depends on the skill of operator. The operator should maintain constant speed of crank rotation in order to obtain uniform spacing. Higher speed of crank rotation will decrease hill to hill spacing and vice-versa. However, row to row spacing was fixed at $20 \mathrm{~cm}$ apart. 


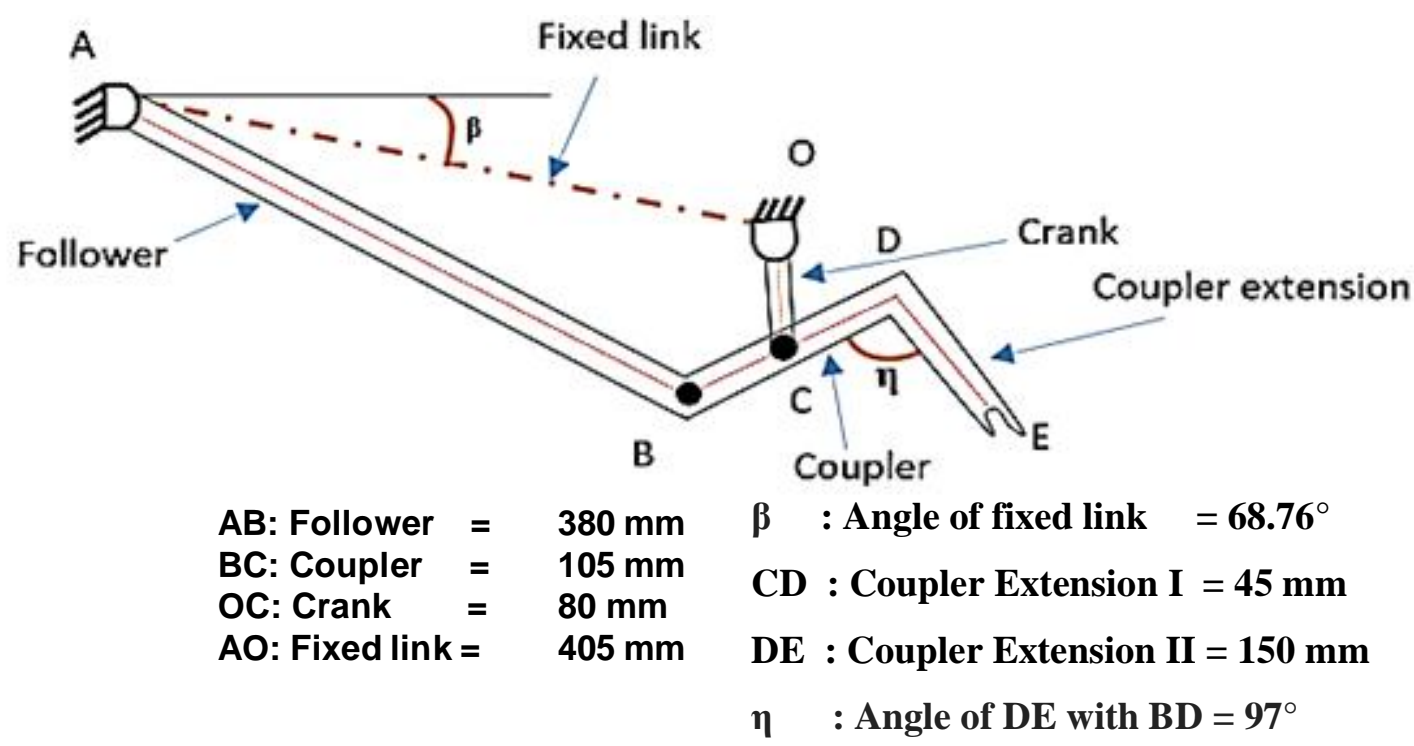

Fig 4: Kinematic diagram of planting mechanism.

\section{e) Planting mechanism}

A 2-dimensional four bar linkage mechanism is used for the planting mechanism. Transplanting finger is attached at the extension of the coupler link. Kinematic diagram of the planting mechanism is shown in Fig 4.

\section{f) Seedling tray}

The seedling tray was fabricated using Gl sheet of size $20 \times 30 \mathrm{~cm}$. A slot of size $20 \mathrm{~mm}$ width was opened for easy passage of seedling during picking. A slot of $8 \mathrm{~mm}$ width was provided for passage of seedling pusher or star wheel. Design of seedling tray is shown in Fig 5.

\section{g) Handle}

The handle used was of MS hollow pipe having a diameter $15 \mathrm{~mm}$. The length of handle was $98 \mathrm{~cm}$ and was inclined at $63^{\circ}$ from horizontal.

\section{h) Frame}

Frame was fabricated using MS angle of $20 \times 20 \times 3 \mathrm{~mm}$. All the other elements including float, handle, linkages, seedling tray and cage wheel and star wheel mechanism are attached to frame.

\section{i) Lugged wheel and star-wheel mechanism}

A lugged wheel and star-wheel mechanism were designed to act as a seedling pusher. The lugged wheel gets power from the ground contact while traveling. On the same shaft, a star wheel is fixed. Hence when the lugged wheel gets rotated, the star wheel also rotates in the same direction in the direction of travel. Thus, the gap in between the teeth of the star wheel pulls down the seedlings up to the finger reach. A photograph of the lugged wheel is shown in Fig 6.

\section{j) Power transmission}

The power is transferred by the rotation of hand crank as

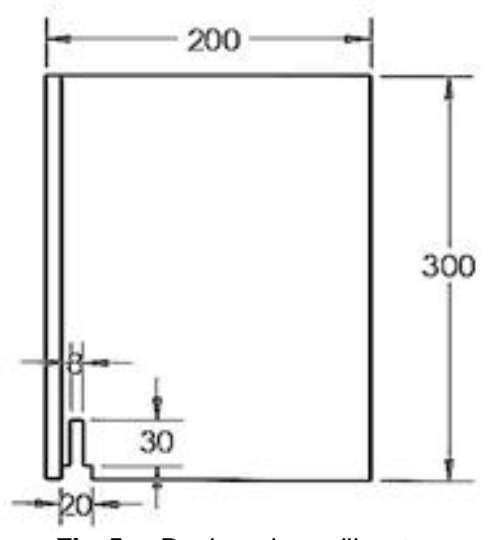

Fig 5a: Designed seedling tray.

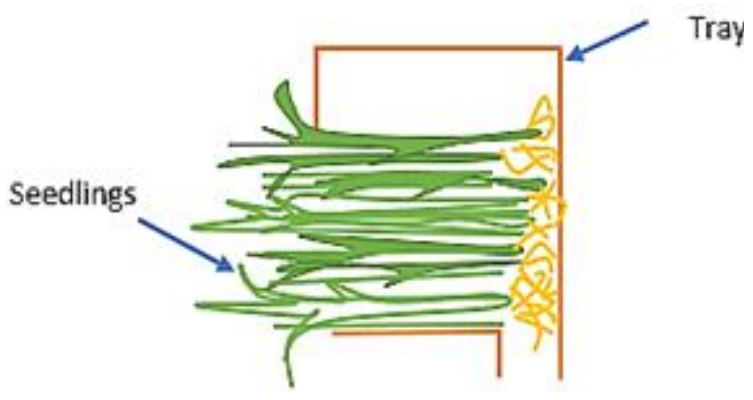

Fig 5b: Placement of seedlings on the tray.

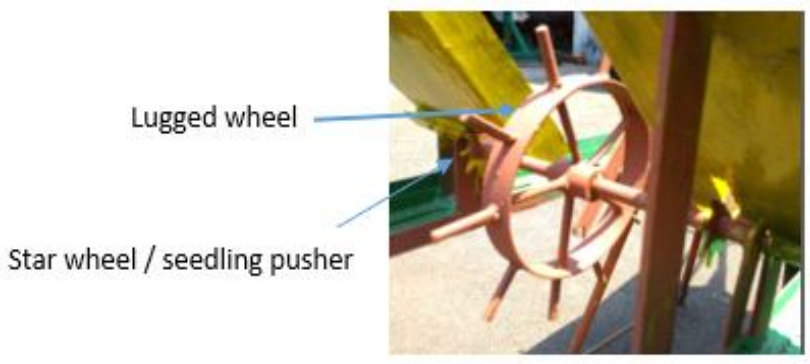

Fig 6: Photograph showing star wheel and lugged wheel. 
shown in Fig. 7. It includes two sprockets connected by a chain. One sprocket with 20 teeth is mounted on the crankshaft of the planting mechanism and other sprocket with 40 teeth is mounted on the handle side. One full rotation of the hand crank provides double planting of seedlings. Centre to center distance between two sprockets was kept at $98 \mathrm{~cm}$. Roller chain having a pitch of $1.27 \mathrm{~cm}$ was used for transmitting power between two sprockets.

\section{k) Steps for operating the machine}

The machine should be operated in the following steps

1. The machine should travel by pulling it in the backward direction

2. One hand (left hand) should pull the handle and the other hand (right hand) should rotate the crank

3. Make sure the seedlings are placed properly and horizontally on the tray

4. The level of water should be at least $3-5 \mathrm{~cm}$ above the soil surface. Less water increases the pull resistance
5. The machine can be pulled and plant the seedling continuously or it can be pulled, stopped at a desired distance and plant the seedlings and repeat the same process.

\section{I) Performance evaluation of the developed transplanter}

The developed prototype was tested in the agricultural field at IIT Kharagpur. The field was plowed to a depth of $15 \mathrm{~cm}$ and then puddled. The puddle soil was then leveled and was kept undisturbed for one day before testing. The machine was checked and tested in the laboratory to make sure that all the links and parts are working properly as required. The laboratory test mainly deals with the proper picking of seedlings from the tray and the number of seedlings picks per stroke of the finger. The machine was then put in the field condition. Before operating the machine, necessary adjustments like arrangements of seedlings and placement of seedlings on the tray were made and hence no time was wasted during the experiment. The speed of

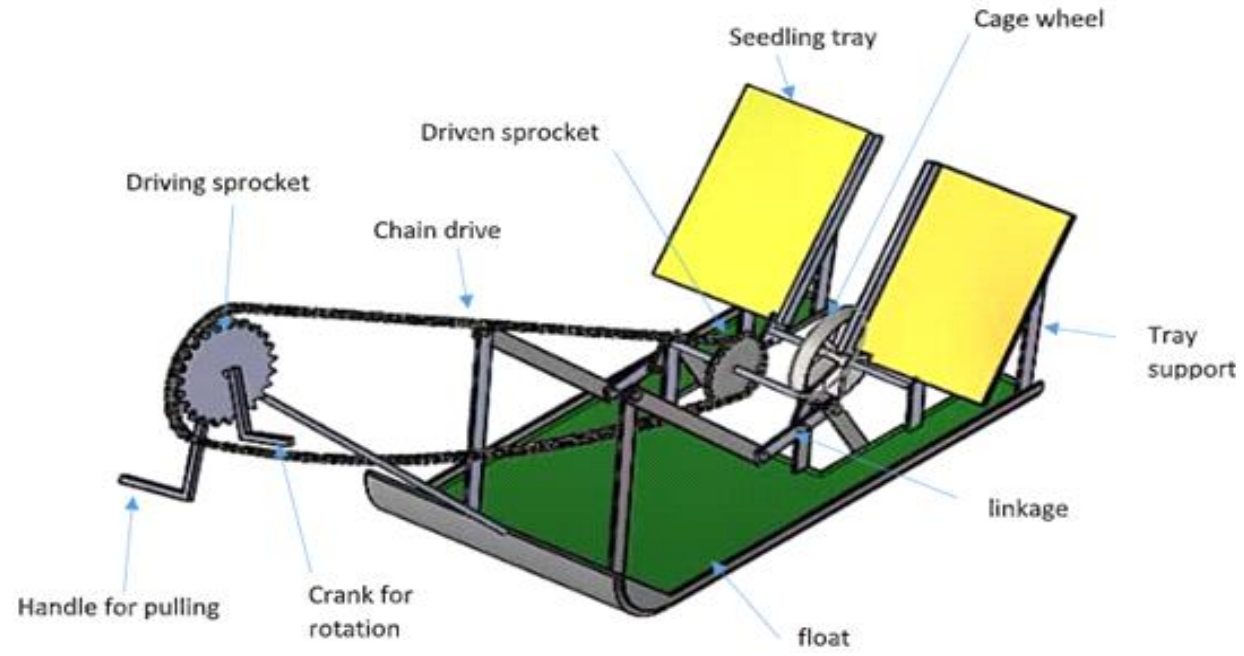

Fig 7: Designed prototype (using Solid works software).

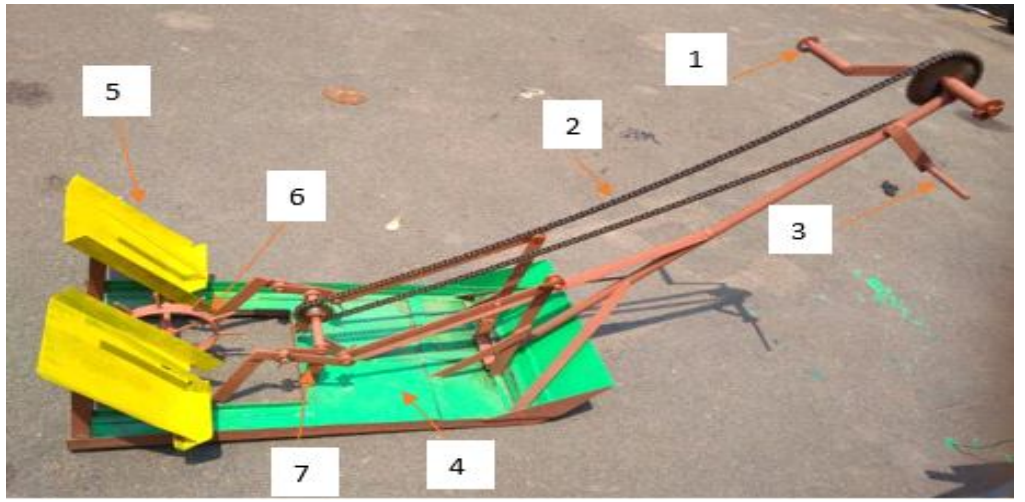

1. Handle for driving sprocket; 2. Chain drive; 3. Handle for pulling; 4. Float; 5. Seedling tray; 6. Lugged wheel; 7. Four-bar linkage mechanism

Fig 8: Photograph showing the developed prototype. 
operation of the machine at $0.5 \mathrm{kmph}$ was found to be suitable. However, it depends on the skill of the workers. Plant to plant spacing is to be maintained by the operator. Increasing the speed of operation likely to increase plant to plant spacing and vice-versa.

\section{RESULTS AND DISCUSSION}

The two-row manually operated paddy transplanter was developed and fabricated in the workshop of the Agricultural and Food Engineering Department of IIT Kharagpur, West Bengal as shown in Fig 8. The specifications of the machine are given in Table 1. The transplanter was tested in the laboratory as well as on the actual field condition. The various characteristics of paddy seedlings that were used for testings were given in Table 2. Laboratory test result (Table 4) shows that the transplanting mechanism functions properly and it shows that the finger can pick on an average of 5 seedlings per stroke. There were high values of standard deviation in the lab test. This may be due to the reason that during the test, the machine was kept above the ground and that the lugged wheel and star wheel were not involved in delivering the seedlings to the finger. However, this was not the problem during the field tests as given in Table 3 . The lab test was done to check if the finger can pick the seedlings properly. The average plant to plant spacing was $17.18 \mathrm{~cm}$. Constant row spacing of $20 \mathrm{~cm}$ was maintained

Table 1: Detail specifications of the machine.

\begin{tabular}{ll}
\hline Particulars & Specifications \\
\hline Length $(\mathrm{mm})$ & 740 \\
Width $(\mathrm{mm})$ & 410 \\
Weight $(\mathrm{kg})$ & 19 \\
Row to row spacing $(\mathrm{cm})$ & 20 \\
Number of rows & 2 \\
Float & MS sheet of $3 \mathrm{~mm}$ thicknessSize: $740 \mathrm{~mm} \times 410 \mathrm{~mm}$ \\
Seedling tray & Gl sheet of $18 \mathrm{gauge}$ \\
Lugged wheel & Diameter: $150 \mathrm{~mm}$; Number of lugs: 10 ; Number of spokes: 5 \\
Star wheel/seedling pusher & Diameter: $70 \mathrm{~mm}$; Number of teeth: 14 \\
Power transmission system & Chain and sprocket systemNumber of teeth on driver sprocket $=40$ Number of teeth \\
& on driven sprocket $=20$ Pitch of the chain $=12 \mathrm{~mm}$ \\
Types of finger used & Fixed fork type \\
Picking mechanism & Four bar linkage with coupler extension \\
\hline
\end{tabular}

Table 2: Various characteristics of paddy seedlings.

\begin{tabular}{|c|c|c|c|c|c|c|c|c|c|c|c|}
\hline Parameters & Values & Avg. & & & & & & & & & \\
\hline Height $(\mathrm{cm})$ & 28 & 16 & 19 & 16 & 16.5 & 29 & 18 & 22 & 22.5 & 21 & 20.8 \\
\hline Major axis (mm) & 6 & 2 & 2 & 1.5 & 2 & 3 & 3 & 4 & 3 & 2.5 & 2.6 \\
\hline Minor axis $(\mathrm{mm})$ & 2 & 1 & 1 & 0.5 & 1 & 1.5 & 1 & 1.5 & 1 & 1.5 & 1.2 \\
\hline Area of cross section $\left(\mathrm{mm}^{2}\right)$ & 37.68 & 6.28 & 6.28 & 2.35 & 6.28 & 14.13 & 9.42 & 18.84 & 9.42 & 11.77 & 12.24 \\
\hline
\end{tabular}

Table 3: Different parameters of readings from field tests.

\begin{tabular}{lcccccccccccc}
\hline Parameters & \multicolumn{1}{c}{ Values } & \multicolumn{1}{c}{ Mean } & SD \\
\hline Planting depth $(\mathrm{cm})$ & 3.5 & 3 & 4 & 4.5 & 3 & 5 & 3.8 & 4.2 & 4 & 3.8 & 3.88 & 0.62 \\
Plant to plant spacing (cm) & 15 & 14.5 & 16.3 & 18 & 16.5 & 20 & 19.5 & 16.5 & 17 & 18.5 & 17.18 & 1.81 \\
No. of seedlings per hill & 7 & 6 & 5 & 4 & 0 & 5 & 6 & 5 & 4 & 3 & 4.44 & 1.95 \\
Angle of stand of seedlings $\left(^{\circ}\right)$ per $\mathrm{m}^{2}$ & 78 & 80 & 83.5 & 88 & 86 & 73.5 & 84 & 81.5 & 79 & 89 & 82.25 & 4.56 \\
Row to row spacing, $\mathrm{cm}$ & 20 & 20 & 20 & 20 & 20 & 20 & 20 & 20 & 20 & 20 & 20 & 0 \\
Missing hills $/ \mathrm{m}^{2}$ & 3 & 5 & 1 & 4 & 5 & 3 & 2 & 2 & 4 & 3 & 3.2 & 1.25 \\
No. of persons required to operate the machine & 1 & 1 & 1 & 1 & 1 & 1 & 1 & 1 & 1 & 1 & 1 & 0 \\
\hline
\end{tabular}

Table 4: Observations of the number of seedlings pick by transplanter fingers in laboratory tests.

\begin{tabular}{|c|c|c|c|c|c|c|c|c|c|c|c|c|}
\hline Finger & & & & & & alues & & & & & Mean & SD \\
\hline 1 & 8 & 6 & 6 & 2 & 0 & 4 & 7 & 2 & 1 & 4 & 4 & 3.46 \\
\hline 2 & 7 & 6 & 7 & 6 & 0 & 3 & 1 & 0 & 2 & 2 & 3.4 & 3.33 \\
\hline
\end{tabular}


Table 5: Force required to pull the machine.

\begin{tabular}{lccc}
\hline $\begin{array}{l}\text { Sl. } \\
\text { No. }\end{array}$ & $\begin{array}{c}\text { Pull, } \\
\mathrm{kg}\end{array}$ & $\begin{array}{c}\text { Draft }=\mathrm{PCos} \theta, \\
\mathrm{kg}\end{array}$ & $\begin{array}{c}\text { Angle of } \\
\text { inclination, } \theta\end{array}$ \\
\hline 1 & 8.20 & 3.72 & $63^{\circ}$ \\
2 & 9.30 & 4.22 & \\
3 & 8.65 & 3.90 & \\
4 & 8.93 & 4.05 & \\
5 & 9.20 & 4.17 & $63^{\circ}$ \\
\hline
\end{tabular}

as per the design. The number of seedlings per hill was 4.44. The angle of the standing of seedlings per hill was $82.25^{\circ}$. The depth of planting was $3.88 \mathrm{~cm}$. Missing hills per square meter was 3.2. The average force required to pull the machine was found to be $8.856 \mathrm{~kg}$ with the corresponding average draft of $4.02 \mathrm{~kg}$ as calculated in Table 5 .

\section{CONCLUSION}

The performance of the developed prototype was satisfactory. The fixed fork finger traversed the path in the form of a loop as per the theoretical design. The designed fixed fork finger type can hold 5 to 8 seedlings at a time. However, the number of seedlings to be held by the finger depends on the size and density of seedlings too. The forward speed of operation at $0.5 \mathrm{kmph}$ was found to be comfortable. The actual field capacity of the two-row machine was $0.02 \mathrm{ha} / \mathrm{h}$.

\section{REFERENCES}

Anonymous (1979). Rice Transplanter Regional Network for Agricultural Machinery. RNAM Digest 1 Los Banos, Philippines pp 1-24.

Anonymous, (2013). Area, production and yield of rice in India.

Choudhury, A.K. (1983). Design and Development of a Six-Row Manually Operated Paddy Transplanter. Unpublished M.tech Thesis, IIT Kharagpur.

Chaitanya, D.N.V., Arunkumar, S., Akhilesh, G.B., Kumara, G.S., Babua, K.N.V.S.A. (2018). Design of Rice Transplanter. IOP Conf. Series: Materials Science and Engineering. 377(2018) 012037 doi:10.1088/1757-899X/377/1/012037.

Dixit, A., Khurana, R., Singh J. and Singh, G. (2007). Comparative Performance of Different Paddy Transplanters Developed in India- A Review. Agric. Rev. 28(4): 262-269.

Gaikwad, P.B., Shahare, P.U., Pathak, S.V. and Aware, V.V. (2014). Development and performance evaluation of four row self-propelled paddy transplanter. International Journal of Agricultural Engineering. 8(1): 9-14.

Singh, G., Sharma, T. R., Bockhop, C.W., (1985). Field Performance Evaluation of a Manual Rice Transplanter. J. Agric. Engg. Res. 32: 259-268.

Thomas, E.V. (2002). Development of a mechanism for transplanting rice seedlings. Mechanism and Machine Theory. 37: 395410.

Wang, W., Liang, Z., Yang, F., Ma, H., Huang, L. and Liu, M. (2010). Effects of number of seedlings per hill on rice biomass partitioning and yield in a saline-sodic soil. Journal of Food, Agriculture and Environment. 8(2): 628-633. 